\title{
Using latent class analysis to develop a model of the relationship between socioeconomic position and ethnicity: cross-sectional analyses from a multi-ethnic birth cohort study
}

Lesley Fairley ${ }^{1 *}$, Baltica Cabieses², Neil Small³, Emily S Petherick¹, Debbie A Lawlor ${ }^{4}$, Kate E Pickett ${ }^{5}$ and John Wright ${ }^{1}$

\begin{abstract}
Background: Almost all studies in health research control or investigate socioeconomic position (SEP) as exposure or confounder. Different measures of SEP capture different aspects of the underlying construct, so efficient methodologies to combine them are needed. SEP and ethnicity are strongly associated, however not all measures of SEP may be appropriate for all ethnic groups.

Methods: We used latent class analysis (LCA) to define subgroups of women with similar SEP profiles using 19 measures of SEP. Data from 11,326 women were used, from eight different ethnic groups but with the majority from White British (40\%) or Pakistani (45\%) backgrounds, who were recruited during pregnancy to the Born in Bradford birth cohort study.

Results: Five distinct SEP subclasses were identified in the LCA: (i) "Least socioeconomically deprived and most educated" (20\%); (ii) "Employed and not materially deprived" (19\%); (iii) "Employed and no access to money" (16\%); (iv) "Benefits and not materially deprived" (29\%) and (v) "Most economically deprived" (16\%). Based on the magnitude of the point estimates, the strongest associations were that compared to White British women, Pakistani and Bangladeshi women were more likely to belong to groups: (iv) "benefits and not materially deprived" (relative risk ratio $(95 \% \mathrm{Cl}): 5.24(4.44,6.19)$ and $3.44(2.37,5.00)$, respectively) or (v) most deprived group $(2.36(1.96,2.84)$ and $3.35(2.21,5.06)$ respectively) compared to the least deprived class. White Other women were more than twice as likely to be in the (iv) "benefits and not materially deprived group" compared to White British women and all ethnic groups, other than the Mixed group, were less likely to be in the (iii) "employed and not materially deprived" group than White British women.

Conclusions: LCA allows different aspects of an individual's SEP to be considered in one multidimensional indicator, which can then be integrated in epidemiological analyses. Ethnicity is strongly associated with these identified subgroups. Findings from this study suggest a careful use of SEP measures in health research, especially when looking at different ethnic groups. Further replication of these findings is needed in other populations.
\end{abstract}

Keywords: Socioeconomic position, Ethnicity, Latent class analysis, Born in Bradford

\footnotetext{
* Correspondence: Lesley.fairley@bthft.nhs.uk

${ }^{1}$ Bradford Institute for Health Research, Bradford Teaching Hospitals NHS

Foundation Trust, Bradford, UK

Full list of author information is available at the end of the article
} 


\section{Background}

Socioeconomic position (SEP), is a multidimensional concept that includes both resource based components (such as income and material wealth) and prestige based components (e.g. education, occupation, societal position amongst peers) and, ideally, takes account of these across the life course [1-4]. It has been emphasised that, whether SEP is being used as the main exposure variable in epidemiological research or as a potential confounder, combining several of these different components is important to fully capture SEP variation [1-3]. However while the definition clearly indicates the need to include multiple components in its assessment, single measures of SEP (such as occupation or educational attainment) are frequently used in research. In part this may reflect the availability of only one or two measurements in a given study, but it may also reflect lack of certainty about how to combine a number of different measurements appropriately, particularly where there are complex patterns of missing data between measurements.

There is also uncertainty about how to determine which measurements best capture the full concept of SEP for different groups, based for example on ethnicity, gender or age [1-6]. For example, women who do not work outside of the home may be classified according to their husband's occupation, but this may or may not reflect their personal material wealth or social standing; similarly previous occupation may not be a good measure of SEP for those past retirement age. Educational attainment might have markedly different meaning for people from different ethnic groups (particularly if education has been received in different countries) $[4,5]$. These differences may also be reflected in patterns of missing data, for example there may be gender and ethnic differences in ability or willingness to answer questions about total household income.

Given its relevance to health research it is important to explore how to efficiently combine multiple measures of SEP together in a meaningful way to the population being researched. Latent class analysis (LCA), is an established statistical method that allows the classification of individuals into groups based on conditional probabilities; within each group individuals will have a similar pattern of response to categorical variables [7]. This approach can also incorporate responses that other analyses may treat as missing data by using a full information maximum likelihood (FIML) approach. This approach does not impute missing values but uses all the available information for each individual to provide maximum likelihood estimations $[8,9]$. This method produces unbiased parameter estimates and standard errors under missing at random and missing completely at random assumptions. LCA is also flexible in the number and types of variables that can be included.
LCA is a data driven approach and is increasingly being applied to health related data. LCA has been used to identify subgroups of study populations based on SEP in different studies in the UK $[10,11]$ the USA $[12,13]$ and the Philippines [14]. These studies found that between 3 and 7 classes best described the SEP profiles of study participants. To our knowledge no previous study has used LCA to identify subgroups of the population in relation to SEP and explore how these classes relate to, or are influenced by, ethnicity.

In order to examine ethnic differences in health it is important to make appropriate adjustment for SEP, assuming that once SEP is considered any ethnic group differences are due to factors linked to ethnicity such as cultural and genetic differences. It is unclear whether gradients in health by SEP in particular ethnic groups are not always found due to poor and inappropriate measurements of SEP for such groups. The aim of this paper was to describe how latent class analysis can be used to help us understand and combine several measures of SEP into one measure in a multi-ethnic population. We did this in two ways. First, we identified different SEP subgroups of a population of women who were recruited during pregnancy from a largely deprived and ethnically diverse city in the North of England and examined the association of ethnicity to these subgroups. This allowed all of the eight different ethnic groups recruited to the cohort to be included in the analyses and examined whether women from different ethnic groups were more or less likely to belong to different SEP subgroups that have been robustly defined using a wide-range of SEP components. Second, we used the LCA approach to identify subgroups based on SEP separately within the two largest ethnic groups in the cohort; White British (comprising $40 \%$ of the participants) and Pakistani origin women $(45 \%)$. This allowed us to examine whether components of SEP would aggregate differently in two distinct ethnic groups. We were only able to do this for the two largest groups as the other six ethnic groups contained too few participants for robust analyses.

\section{Methods}

\section{Data}

The Born in Bradford (BiB) study is a longitudinal multi-ethnic birth cohort study aiming to examine the impact of environmental, psychological and genetic factors on maternal and child health and wellbeing [15]. Bradford is a city in the North of England with high levels of deprivation and ethnic diversity. Pregnant women were recruited at 26-28 weeks gestation. For those consenting, a baseline questionnaire was completed via an interview with a trained study administrator. The full $\mathrm{BiB}$ cohort recruited 12453 mothers who had 13776 pregnancies between 2007 and 2010, of whom 11396 (82.7\%) completed 
the baseline questionnaire. The cohort is broadly characteristic of the city's maternal population [15]. Ethical approval for the data collection was granted by Bradford Research Ethics Committee (Ref 07/H1302/112).

\section{Measures of socioeconomic position}

Within the BiB cohort 19 components of SEP were collected by interview at recruitment. These are described in Table 1 and in the text below.

Over a quarter $(27 \%)$ of all women reported they had never been employed, therefore we were unable to assign an occupational social class to these women. We did, however, include women's employment as a categorical variable: currently employed, previously employed and never employed.

The baby's father's occupation was coded based on the National Statistics Socio-Economic Classification (NS-SEC) classification [16]. Categories were then collapsed into the following: non-manual employment (including modern professional occupations, clerical and intermediate occupations, senior managers or administrators, middle or junior managers, traditional professional occupations and technical and craft occupations), manual employment (including semi-routine manual and service occupations and routine manual and service occupations), selfemployed, student, unemployed (including long term sick) and don't know. We could not use the exact NS-SEC classification, as for some fathers we only had information to indicate that they were self-employed and did not have further information about the type of work they did.

The highest educational qualification obtained by the woman and the baby's father was recorded along with the country it was obtained in. In England pupils sit General Certificate of Secondary Education (GCSE) examinations in different subjects usually at age 14-16, receiving 5 or more GCSEs is usually a requirement for undertaking Advanced level (A-level) studies, which are examinations in different subjects usually taken at age 16-18 before attending university. We equivalised the highest educational qualifications (based on the qualification received and the country obtained) into one of seven categories using UK National Academic Recognition Information Center [17] : $<5$ GCSE equivalent, 5 GCSE equivalent, A- level equivalent, higher than A-level equivalent, other, foreign unknown and don't know. The foreign unknown category relates to responses given that referred to qualifications obtained overseas with insufficient information provided to determine their equivalence and the don't know response relates to the mother or father responding "don't know" during interview.

We included the responses to three questions about the women's financial situation. Women were asked how

Table 1 Summary of SEP variables used in latent class analysis

\begin{tabular}{|c|c|}
\hline Variable description & Category level in analysis \\
\hline Woman's employment status & Currently employed, previously employed, never employed, \\
\hline Baby's father's employment status & Non- manual, manual, self-employed, student, unemployed, don't know \\
\hline Mother's education & $\begin{array}{l}<5 \text { GCSE equivalent, } 5 \text { GCSE equivalent, A-level equivalent, higher than } \\
\text { A-level, other, don't know, foreign unknown }\end{array}$ \\
\hline Baby's father's education & $\begin{array}{l}<5 \text { GCSE equivalent, } 5 \text { GCSE equivalent, A-level equivalent, higher than } \\
\text { A-level, other, don't know, foreign unknown }\end{array}$ \\
\hline Subjective poverty & No, yes \\
\hline Being in receipt of means tested benefits & No, yes \\
\hline Up to date with bills & Yes, no, don't know \\
\hline Housing tenure & $\begin{array}{l}\text { Owns outright, mortgage, lives rent free, private landlord, social housing, } \\
\text { other, don't know }\end{array}$ \\
\hline Able to afford a holiday from home for at least one week once a year & Have or don't want or need, can't afford \\
\hline Able to afford family and friends for a drink or meal at least once a month & Have or don't want or need, can't afford \\
\hline Able to afford two pairs of all weather shoes & Have or don't want or need, can't afford \\
\hline Able to afford enough money to keep home in decent state of decoration & Have or don't want or need, can't afford \\
\hline Able to afford household contents insurance & Have or don't want or need, can't afford \\
\hline Able to afford money to make regular savings of $£ 10$ a month & Have or don't want or need, can't afford \\
\hline Able to afford money to replace any worn out furniture & Have or don't want or need, can't afford \\
\hline Able to afford money to replace or repair major electrical goods & Have or don't want or need, can't afford \\
\hline Able to afford a small amount of money to spend on yourself each week & Have or don't want or need, can't afford \\
\hline Able to afford a hobby or leisure activity & Have or don't want or need, can't afford \\
\hline In winter are you able to keep home warm enough & Have or don't want or need, can't afford \\
\hline
\end{tabular}


Table 2 Characteristics of study population

\begin{tabular}{|c|c|c|c|}
\hline Variable & Category & $\mathrm{n}$ & $\%$ \\
\hline \multirow[t]{8}{*}{ Woman's ethnic group } & White British & 4480 & 39.6 \\
\hline & White Other & 302 & 2.7 \\
\hline & Mixed & 180 & 1.6 \\
\hline & Black & 249 & 2.2 \\
\hline & Indian & 438 & 3.9 \\
\hline & Pakistani & 5117 & 45.2 \\
\hline & Bangladeshi & 263 & 2.3 \\
\hline & Other & 297 & 2.6 \\
\hline \multirow[t]{3}{*}{ Woman's age } & $<20$ years & 814 & 7.2 \\
\hline & 20-34 years & 9164 & 80.9 \\
\hline & $35+$ years & 1348 & 11.9 \\
\hline \multirow[t]{3}{*}{ Marital and cohabitation status } & $\begin{array}{l}\text { Married and living } \\
\text { with partner }\end{array}$ & 7451 & 65.8 \\
\hline & $\begin{array}{l}\text { Not married and living } \\
\text { with partner }\end{array}$ & 2015 & 17.8 \\
\hline & Not living with partner & 1860 & 16.4 \\
\hline \multirow[t]{4}{*}{ Woman's employment status } & Currently employed & 4987 & 44.0 \\
\hline & Previously employed & 3231 & 28.5 \\
\hline & Never employed & 3093 & 27.3 \\
\hline & Missing & 15 & 0.1 \\
\hline \multirow{7}{*}{$\begin{array}{l}\text { Woman's husband/partner } \\
\text { employment status }\end{array}$} & Non- manual & 4338 & 38.3 \\
\hline & Manual & 3687 & 32.6 \\
\hline & Self-employed & 1627 & 14.4 \\
\hline & Student & 185 & 1.6 \\
\hline & Unemployed & 857 & 7.6 \\
\hline & Don't know & 137 & 1.2 \\
\hline & Missing & 495 & 4.4 \\
\hline \multirow[t]{8}{*}{ Woman's education } & $<5$ GCSE equivalent & 2438 & 21.5 \\
\hline & 5 GCSE equivalent & 3469 & 30.6 \\
\hline & A-level equivalent & 1638 & 14.5 \\
\hline & Higher than A-level & 2892 & 25.5 \\
\hline & Other & 625 & 5.5 \\
\hline & Don't know & 127 & 1.1 \\
\hline & Foreign Unknown & 112 & 1.0 \\
\hline & Missing & 25 & 0.2 \\
\hline \multirow[t]{8}{*}{ Baby's father's education } & $<5$ GCSE equivalent & 1731 & 15.3 \\
\hline & 5 GCSE equivalent & 2710 & 23.9 \\
\hline & A-level equivalent & 1156 & 10.2 \\
\hline & Higher than A-level & 2848 & 25.1 \\
\hline & Other & 510 & 4.5 \\
\hline & Don't know & 2228 & 19.7 \\
\hline & Foreign Unknown & 110 & 1.0 \\
\hline & Missing & 33 & 0.3 \\
\hline
\end{tabular}

Table 2 Characteristics of study population (Continued)

\begin{tabular}{|c|c|c|c|}
\hline \multirow[t]{3}{*}{ Subjective poverty } & $\begin{array}{l}\text { No (not subjectively } \\
\text { poor) }\end{array}$ & 10395 & 91.8 \\
\hline & Yes (subjectively poor) & 862 & 7.6 \\
\hline & Missing & 69 & 0.6 \\
\hline \multirow[t]{3}{*}{ Means tested benefits } & No & 6673 & 58.9 \\
\hline & $\begin{array}{l}\text { Yes (receipt of means } \\
\text { tested benefits) }\end{array}$ & 4618 & 40.8 \\
\hline & Missing & 35 & 0.3 \\
\hline \multirow[t]{4}{*}{ Up to date with bills } & Yes & 9793 & 86.5 \\
\hline & No & 1174 & 10.4 \\
\hline & Don't know & 317 & 2.8 \\
\hline & Missing & 42 & 0.4 \\
\hline \multirow[t]{8}{*}{ Housing tenure } & Owns outright & 1580 & 14.0 \\
\hline & Mortgage & 5149 & 45.5 \\
\hline & Rent free & 858 & 7.6 \\
\hline & Private landlord & 2206 & 19.5 \\
\hline & Social housing & 1238 & 10.9 \\
\hline & Other & 144 & 1.3 \\
\hline & Don't know & 128 & 1.1 \\
\hline & Missing & 23 & 0.2 \\
\hline \multirow[t]{3}{*}{$\begin{array}{l}\text { Holiday from home for at least } \\
\text { one week once a year }\end{array}$} & $\begin{array}{l}\text { Have or don't } \\
\text { want or need }\end{array}$ & 7144 & 63.1 \\
\hline & Can't afford & 4084 & 36.1 \\
\hline & Missing & 98 & 0.9 \\
\hline \multirow[t]{3}{*}{$\begin{array}{l}\text { Family and friends for a drink or } \\
\text { meal at least once a month }\end{array}$} & $\begin{array}{l}\text { Have or don't } \\
\text { want or need }\end{array}$ & 11081 & 97.3 \\
\hline & Can't afford & 232 & 2.1 \\
\hline & Missing & 76 & 0.7 \\
\hline \multirow[t]{3}{*}{ Two pairs of all weather shoes } & $\begin{array}{l}\text { Have or don't } \\
\text { want or need }\end{array}$ & 11035 & 97.4 \\
\hline & Can't afford & 244 & 2.2 \\
\hline & Missing & 47 & 0.4 \\
\hline \multirow[t]{3}{*}{$\begin{array}{l}\text { Enough money to keep home in } \\
\text { decent state of decoration }\end{array}$} & $\begin{array}{l}\text { Have or don't } \\
\text { want or need }\end{array}$ & 10181 & 89.9 \\
\hline & Can't afford & 1053 & 9.3 \\
\hline & Missing & 92 & 0.8 \\
\hline \multirow[t]{3}{*}{ Household contents insurance } & $\begin{array}{l}\text { Have or don't } \\
\text { want or need }\end{array}$ & 8715 & 77.0 \\
\hline & Can't afford & 1320 & 11.7 \\
\hline & Missing & 1291 & 11.4 \\
\hline \multirow[t]{3}{*}{$\begin{array}{l}\text { Money to make regular savings of } \\
£ 10 \text { a month }\end{array}$} & $\begin{array}{l}\text { Have or don't } \\
\text { want or need }\end{array}$ & 8094 & 71.5 \\
\hline & Can't afford & 2395 & 21.2 \\
\hline & Missing & 837 & 7.4 \\
\hline \multirow[t]{3}{*}{$\begin{array}{l}\text { Money to replace any worn out } \\
\text { furniture }\end{array}$} & $\begin{array}{l}\text { Have or don't } \\
\text { want or need }\end{array}$ & 8151 & 72.0 \\
\hline & Can't afford & 2992 & 26.4 \\
\hline & Missing & 183 & 1.6 \\
\hline
\end{tabular}


Table 2 Characteristics of study population (Continued)

\begin{tabular}{llll}
\hline $\begin{array}{lll}\text { Money to replace or repair } \\
\text { major electrical goods }\end{array}$ & Have or don't & 8553 & 75.5 \\
& want or need & & \\
& Can't afford & 2595 & 22.9 \\
& Missing & 178 & 1.6 \\
A small amount of money to & Have or don't & 9406 & 83.1 \\
spend on yourself each week & want or need & & \\
& Can't afford & 1839 & 16.2 \\
& Missing & 81 & 0.7 \\
A hobby or leisure activity & Have or don't & 10580 & 93.4 \\
& want or need & & \\
& Can't afford & 664 & 5.9 \\
& Missing & 82 & 0.7 \\
In winter are you able to keep & Have or don't & 10852 & 95.8 \\
home warm enough & want or need & & \\
\hline & Can't afford & 394 & 3.5 \\
& Missing & 80 & 0.7 \\
\hline
\end{tabular}

difficult they were finding it to get by financially and were classified as subjectively poor if they responded "finding it very difficult" or "finding it quite difficult". Being in receipt of means tested benefits was defined as receiving any of the following: income support, income tested jobs seekers allowance, working families tax credit or housing benefit [18]. Finally we included a categorical variable to indicate if the women were up to date with all their household bills.

Eleven questions about ownership of material items and goods based on questions from the Households Below Average Income Survey [19] were asked. The questions asked if they were able to have; a holiday from home for at least one week once a year (not including staying with relatives in their home), friends and family round for a drink or meal at your house at least once a month, two pairs of all weather shoes, enough money to keep your home in a decent state of repair, household contents insurance, money to make regular savings of $£ 10$ a month, money to replace any worn out furniture, money to replace or repair major electrical goods, a small amount of money to spend each week on yourself, a hobby or leisure activity, in winter are you able to keep your home warm enough. All the responses to these questions were coded as either "have or don't want or need" or "can't afford".

Housing tenure was categorised into one of seven groups; owns outright, owns with a mortgage, lives rent free, owned by a private landlord, living in social housing, other and don't know.

\section{Ethnicity}

Questions relating to ethnicity were based on guidance from the Office for National Statistics [20], and comprised one question asking which ethnic group the mother considered themselves as belonging to (White, Mixed, Black or Black British, Asian or Asian British, Chinese or Other), followed by a further question, based on their response, about cultural background. This resulted in 8 ethnic groups in this analysis; White British, White Other, Mixed, Black, Indian, Pakistani, Bangladeshi and Other.

\section{Other characteristics}

Although few characteristics could influence a woman's ethnicity and therefore confound the association between ethnicity and SEP we felt it was important to consider two key characteristics that may be relevant in explaining the association between ethnicity and SEP. Several of the SEP indicators may be dependent on age and marital status and the distributions of these two variables differed by ethnicity, therefore we felt it was important to explore the effect of adjusting for these in our models. Woman's age at recruitment into the study was categorised as $<21$ years, 21-34 years or 35+ years. Marital and cohabitation status were coded as married, cohabiting or not cohabiting.

\section{Missing data}

Women with missing data on at least one of the covariables (ethnicity, age and marital and cohabitation status) were excluded from all analysis, 49 women had missing ethnicity data and 25 had missing data on marital and cohabitation status. In total 70 cases (0.6\%) were excluded from analysis, leaving a total of 11326 women in the study sample.

\section{Statistical analysis}

\section{Latent Class Analysis}

Latent class analysis (LCA) was used to define groups of women with similar SEP profiles across the 19 determinants of SEP. LCA is a statistical method that allows the classification of individuals into groups based on conditional probabilities, within each class individuals will have a similar pattern of response to categorical variables [7]. This approach can also incorporate responses that other analyses may treat as missing data using the FIML approach $[8,9]$. The main assumption for LCA is conditional independence, that is within each class all measures are independent as all correlation between the variables is explained through the class structure.

Latent class models with 2 to 10 classes were fitted to items measuring different aspects of the women's SEP. Variables were entered into the models as either binary or nominal variables. Latent Class Analyses were carried out in Mplus V6 [21]. Criteria used to select the final LCA model [22] included the change in likelihood between models, Bayesian Information criterion (BIC) and entropy. The percentage change in the log-likelihood was compared for each model, selecting models where there was not too much discernable difference by adding another 
class. BIC is a measure of model fit with penalization for additional classes; models with lower values are considered a better model fit. Entropy measures how well an individual fits into a specific class with values ranging from 0 to 1 with values closer to 1 indicating better fit. We also considered the interpretability of the chosen model [23] by examining the probability of each level of the SEP indicators in each class to try to establish which variables distinguish each group from the others. After selecting the final LCA model, the posterior probability of belonging to each group can be obtained for each individual.

Association of ethnicity with SEP latent class membership Multinomial regression was used to assess the association between ethnicity and membership of the latent classes. The least socioeconomically deprived class was chosen as the reference category and models were weighted by probability of class membership. Unadjusted and adjusted models (adjusting for woman's age and marital status) were fitted. Coefficients from these models were exponentiated to obtain relative risk ratios (RRR) with 95\% confidence intervals. Multinomial regression was carried out in Stata 12 [24].

\section{Stratified LCA models for White British and Pakistani women only}

As our sample was predominantly made up of two ethnic groups (40\% White British and 45\% Pakistani) we further explored the relationship between SEP indicators within these two groups only as the other six ethnic groups contained too few participants for robust analyses.

Latent class models were also run for the White British and Pakistani groups separately using the same methodology as described above.

\section{Results}

Study sample

Table 2 describes the study sample; $40 \%$ of the women were White British and 45\% were of Pakistani origin, 7\% of women were under 20 years of age and $66 \%$ were married and living with a partner.

\section{LCA results}

The 3, 4 and 5 class models showed similar model fit in terms of likelihood, BIC and entropy (Table 3); however based on interpretability we decided that the 5 class model best described the different socioeconomic characteristics of the women in this study. We used the profiles of the different classes to describe the different groups and assign brief labels to them.

We assigned the following labels to the groups; (i) "Least socioeconomically deprived and most educated" (20\% n = 2231 (based on most likely class membership)), (ii) "Employed and not materially deprived" (19\%, n = 2248),
Table 3 Model fit statistics for Latent Class analysis models with 1 to 10 classes

\begin{tabular}{lllll}
\hline Number of classes & Log-likelihood & $\begin{array}{l}\text { \% reduction } \\
\text { in L }\end{array}$ & BIC & Entropy \\
\hline 1 & -141158 & 0 & 282689 & 1.0 \\
2 & -129500 & 8.3 & 259757 & 0.86 \\
3 & -127143 & 9.9 & 255426 & 0.77 \\
4 & -126197 & 10.6 & 253915 & 0.76 \\
5 & -125536 & 11.1 & 252977 & 0.77 \\
6 & -125012 & 11.4 & 252312 & 0.74 \\
7 & -124654 & 11.7 & 251978 & 0.75 \\
8 & -124335 & 11.9 & 251722 & 0.75 \\
9 & -124055 & 12.1 & 251545 & 0.76 \\
10 & -123816 & 12.3 & 251450 & 0.75 \\
\hline
\end{tabular}

(iii) "Employed and no access to money" (16\%, $\mathrm{n}=1722)$, (iv) "Benefits and not materially deprived" $(29 \%, \mathrm{n}=3325)$ and (v) "Most economically deprived" (16\%, n = 1800). The probabilities for selected categories of the SEP indicators within each class are shown in Figure 1 and a brief description of each group is given in Table 4 .

\section{Association between ethnicity and LCA subgroups}

In the multinomial models the "least socioeconomically deprived and most educated" group was used as the reference category (Table 5). Compared to White British women, all ethnic groups other than the Mixed group were less likely to be in the "employed and not materially deprived" group. Women of Mixed, Pakistani and Bangladeshi ethnicities were more likely to be in the "benefits and not materially deprived group" compared to White British women (adjusted RRR $=2.37$ (95\% CI 1.31 to 4.27 ), RRR $=5.24$ (95\% CI 4.44 to 6.19 ) and $R R R=3.44$ (95\% CI 2.37 to 5.00 ) respectively). The risk of being in the most economically deprived group compared to the least deprived and most educated group was lower for women of White Other, Indian, Other ethnicities (adjusted RRR $=0.52$ (95\% CI 0.33 to 0.80), $\mathrm{RRR}=0.26$ (95\% CI 0.15 to 0.45$)$ and $\mathrm{RRR}=0.57$ (95\% CI 0.38 to 0.85 ) respectively) compared to White British women. The risk of membership of this class was greater for women of Pakistani and Bangladeshi origin compared to White British women (adjusted RRR = 2.36 (95\% CI 1.96 to 2.84 ), $\mathrm{RRR}=3.35$ (95\% CI 2.21 to 5.06 ) respectively).

\section{Stratified LCA models for White British and Pakistani women only}

For the White British women based on the model fit statistics and interpretability of the classes we chose the 4 class model. Likewise for the Pakistani women we also chose the 4 class model based on the model fit statistics and interpretability of the classes. We used the 


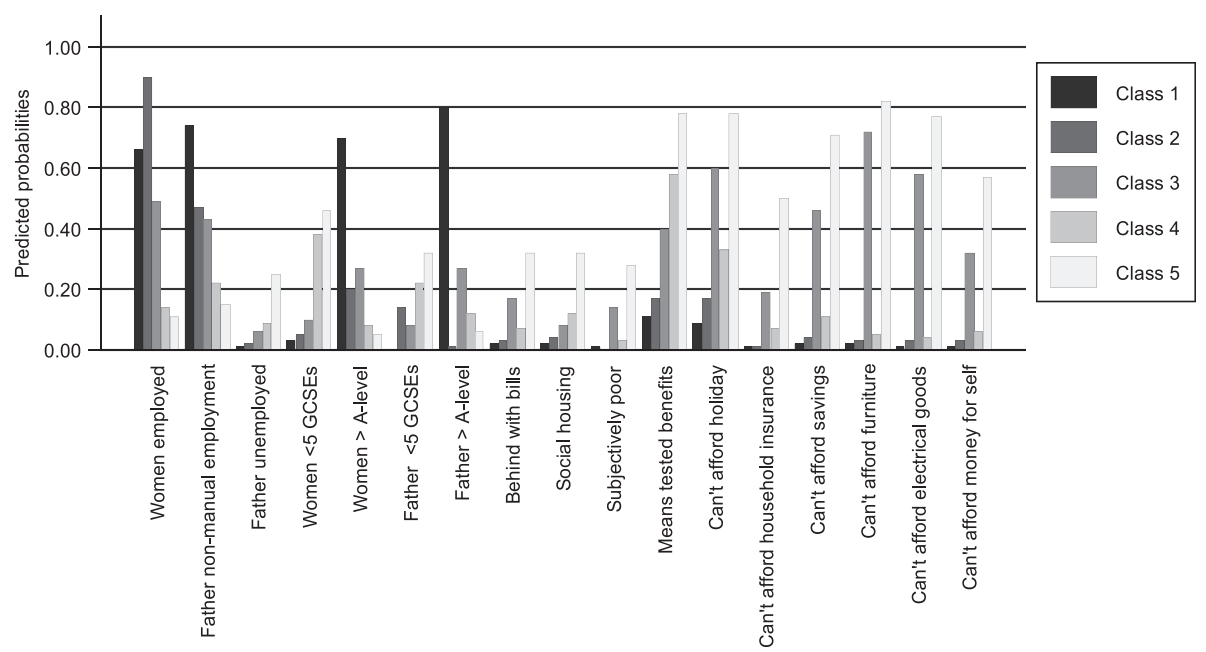

Figure 1 Summary of selected predicted probabilities for levels of SEP indicators from $\mathbf{5}$ class model for all women. Class 1: "Least socioeconomically deprived and most educated" (20\%, $n=2231$ (based on most likely class membership)). Class 2: "Employed, not materially deprived" (19\%, $n=2248)$. Class 3: "Employed, no access to money" $(16 \%, n=1722)$. Class 4: "Benefits not materially deprived" $(29 \%, n=3325)$. Class 5: "Most economically deprived" (16\%, $n=1800)$.

profiles of the different classes to describe the different groups and assign brief labels to these groups.

Tables 6 and 7 and Figures 2 and 3 describe the latent class profiles for the analysis stratified by ethnic group for White British and Pakistani women. Although for both ethnic groups a four class model was selected the characteristics and relative sizes of the four classes differed for each ethnic group. For the White British women the four classes can be described as (i) "Employed, educated and not materially deprived" (44\%, $\mathrm{n}=2038$ (based on most likely class membership)), (ii) "Employed, moderate education, materially deprived" ( $14 \%, \mathrm{n}=614$ ), (iii) "Low education, benefits not materially deprived" $(23 \%, \mathrm{n}=992)$ and (iv) "Low education, benefits, subjectively poor and materially deprived" $(18 \%, \mathrm{n}=836)$. For the Pakistani women the groups can be defined as (i) "Educated, low benefits, not materially deprived" $(22 \%, \mathrm{n}=1113)$, (ii) "Women employed, moderate education, benefits, not materially deprived" (17\%, N=935), (iii) "Women not employed, low education, benefits, not materially deprived" (33\%, $\mathrm{n}=1642)$ and (iv) "Women not employed, moderate education, benefits, subjectively poor and materially deprived" $(28 \%, \mathrm{n}=1427)$. For the two ethnic groups there were marked differences in the classes by the woman's employment status and education. Within the White British group two classes can be described as materially deprived whereas within the Pakistani group only one class were materially deprived.

\section{Discussion}

Using data from a large multi-ethnic birth cohort we used latent class analysis to define an interpretable set of five classes with different SEP profiles. This method allows the combination of many different dimensions of SEP into one overall SEP measure. The five classes ranged in size from $16 \%$ to $29 \%$ of our cohort and included an affluent well educated class, a class of women who were mainly working and were not materially deprived, a group who were also working but were materially deprived, a group with high uptake of benefits but low levels of material deprivation and finally a group with low levels of employment and education, high uptake of benefits and high levels of material deprivation. Membership of these classes were associated with ethnicity and further analysis conducted separately for White British and Pakistani women found that different components of SEP aggregated differently in these two ethnic groups.

Other studies have also used LCA as a method to combine several dimensions of SEP into one indicator [10-14]. In this study the method provided a detailed description of the SEP profile of a multi-ethnic population of pregnant women with a level of detail that would not have been picked up using more traditional indicators of SEP, such as education or occupation. For example in the overall analysis there were two groups that were subjectively poor and did not have access to money to pay bills or buy and replace household goods. However, these groups had very different profiles in terms of employment and education suggesting that there are multiple pathways by which different determinants of SEP can lead to similarly poor outcomes.

The ethnic specific analysis further highlights that different measures of SEP are relevant in different ethnic groups. Although a four class model was selected for both the White British and Pakistani groups the 
Table 4 Description of latent classes from 5 class model solution for all ethnic groups

\begin{tabular}{|c|c|c|}
\hline Class & $\begin{array}{l}\text { Size of } \\
\text { class (nt) }\end{array}$ & Description \\
\hline \multirow[t]{8}{*}{ "Least socioeconomically deprived and most educated" } & $20 \%(n=2231)$ & Women currently and previously employed \\
\hline & & Father non-manual employment \\
\hline & & Women and fathers highly educated \\
\hline & & Up to date with bills \\
\hline & & Mortgage \\
\hline & & Not subjectively poor \\
\hline & & Not receiving means tested benefits \\
\hline & & Not materially deprived \\
\hline \multirow[t]{8}{*}{ "Employed, not materially deprived" } & $19 \%(n=2248)$ & Women currently employed \\
\hline & & Father manual and non-manual employment \\
\hline & & Women and father medium levels of education \\
\hline & & Up to date with bills \\
\hline & & Mortgage \\
\hline & & Not subjectively poor \\
\hline & & Not receiving means tested benefits \\
\hline & & Not materially deprived \\
\hline \multirow[t]{8}{*}{ "Employed, no access to money" } & $16 \%(n=1722)$ & Women currently and previously employed \\
\hline & & Father manual and non-manual employment \\
\hline & & Women and fathers medium levels of education \\
\hline & & Moderate behind with bills \\
\hline & & Mortgage and private renting \\
\hline & & Moderate subjective poverty \\
\hline & & Moderate receipt of means tested benefits \\
\hline & & $\begin{array}{l}\text { Materially deprived in particular can't afford holidays, money to } \\
\text { replace goods and savings }\end{array}$ \\
\hline \multirow[t]{8}{*}{ "Benefits and not materially deprived" } & $29 \%(n=3325)$ & Women low current employment, \\
\hline & & Father manual employment and self-employed \\
\hline & & $\begin{array}{l}\text { Women and fathers low levels of education, fathers education high } \\
\text { don't know response }\end{array}$ \\
\hline & & Up to date with bills \\
\hline & & Owns house outright \\
\hline & & Not subjectively poor \\
\hline & & High receipt of means tested benefits \\
\hline & & Not materially deprived \\
\hline \multirow[t]{8}{*}{ "Most economically deprived" } & $16 \%(n=1800)$ & Women low current employment \\
\hline & & Father manual employment and unemployed \\
\hline & & $\begin{array}{l}\text { Women and fathers low levels of education, fathers education } \\
\text { high don't know response }\end{array}$ \\
\hline & & Behind with bills \\
\hline & & Private renting and social housing \\
\hline & & Subjectively poor \\
\hline & & Highest receipt of means tested benefits \\
\hline & & Materially deprived \\
\hline
\end{tabular}


Table 5 Relative Risk Ratios (RRR) and 95\% CI results for membership of the latent classes compared to the “Least socioeconomically deprived and most educated" group from multinomial models weighted by probability of class membership

\begin{tabular}{|c|c|c|c|c|c|c|c|c|c|c|c|c|c|c|c|c|}
\hline & \multicolumn{4}{|c|}{ Employed not materially deprived } & \multicolumn{4}{|c|}{ Employed no access to money } & \multicolumn{4}{|c|}{ Benefits not materially deprived } & \multicolumn{4}{|c|}{ Most deprived } \\
\hline & \multicolumn{2}{|c|}{ Unadjusted } & \multicolumn{2}{|c|}{ Adjustedt } & \multicolumn{2}{|c|}{ Unadjusted } & \multicolumn{2}{|c|}{ Adjusted $†$} & \multicolumn{2}{|c|}{ Unadjusted } & \multicolumn{2}{|c|}{ Adjusted $†$} & \multicolumn{2}{|c|}{ Unadjusted } & \multicolumn{2}{|c|}{ Adjusted +} \\
\hline & RRR & $95 \% \mathrm{Cl}$ & RRR & $95 \% \mathrm{Cl}$ & RRR & $95 \% \mathrm{Cl}$ & RRR & $95 \% \mathrm{Cl}$ & RRR & $95 \% \mathrm{Cl}$ & RRR & $95 \% \mathrm{Cl}$ & RRR & $95 \% \mathrm{Cl}$ & RRR & $95 \% \mathrm{Cl}$ \\
\hline \multicolumn{17}{|l|}{ Ethnic group } \\
\hline White British & 1 & & 1 & & 1 & & 1 & & 1 & & 1 & & 1 & & 1 & \\
\hline White Other & 0.50 & $(0.37,0.69)$ & 0.58 & $(0.42,0.80)$ & 0.81 & $(0.58,1.13)$ & 1.04 & $(0.73,1.46)$ & 0.39 & $(0.26,0.57)$ & 0.54 & $(0.36,0.82)$ & 0.31 & $(0.21,0.47)$ & 0.52 & $(0.33,0.80)$ \\
\hline Mixed & 1.37 & $(0.77,2.45)$ & 1.33 & $(0.74,2.39)$ & 1.76 & $(0.94,3.28)$ & 1.52 & $(0.80,2.89)$ & 3.15 & $(1.80,5.51)$ & 2.37 & $(1.31,4.27)$ & 2.34 & $(1.32,4.15)$ & 1.68 & $(0.91,3.10)$ \\
\hline Black & 0.19 & $(0.12,0.30)$ & 0.23 & $(0.15,0.37)$ & 0.96 & $(0.68,1.37)$ & 1.22 & $(0.85,1.76)$ & 0.33 & $(0.21,0.53)$ & 0.47 & $(0.29,0.76)$ & 0.75 & $(0.53,1.07)$ & 1.03 & $(0.70,1.53)$ \\
\hline Indian & 0.22 & $(0.17,0.29)$ & 0.35 & $(0.26,0.47)$ & 0.33 & $(0.24,0.44)$ & 0.66 & $(0.48,0.92)$ & 0.36 & $(0.27,0.48)$ & 0.88 & $(0.65,1.20)$ & 0.06 & $(0.04,0.11)$ & 0.26 & $(0.15,0.45)$ \\
\hline Pakistani & 0.29 & $(0.25,0.33)$ & 0.46 & $(0.39,0.54)$ & 0.94 & $(0.82,1.08)$ & 1.86 & $(1.56,2.21)$ & 2.23 & $(1.97,2.52)$ & 5.24 & $(4.44,6.19)$ & 0.63 & $(0.55,0.73)$ & 2.36 & $(1.96,2.84)$ \\
\hline Bangladeshi & 0.26 & $(0.16,0.43)$ & 0.42 & $(0.26,0.68)$ & 0.93 & $(0.62,1.39)$ & 1.85 & $(1.22,2.81)$ & 1.44 & $(1.01,2.05)$ & 3.44 & $(2.37,5.00)$ & 0.86 & $(0.58,1.26)$ & 3.35 & $(2.21,5.06)$ \\
\hline Other & 0.15 & $(0.10,0.22)$ & 0.21 & $(0.15,0.32)$ & 0.43 & $(0.31,0.61)$ & 0.73 & $(0.52,1.04)$ & 0.27 & $(0.19,0.40)$ & 0.51 & $(0.35,0.76)$ & 0.24 & $(0.16,0.35)$ & 0.57 & $(0.38,0.85)$ \\
\hline
\end{tabular}

†Model adjusted for woman's age and marital status. 
Table 6 Description of latent classes from 4 class model solution for White British women

\begin{tabular}{|c|c|c|}
\hline Class & $\begin{array}{l}\text { Size of } \\
\text { class }(n+)\end{array}$ & Description \\
\hline \multirow[t]{8}{*}{ "Employed, educated, not materially deprived" } & \multirow[t]{8}{*}{$44 \%(n=2038)$} & Women currently employed \\
\hline & & Father non-manual employment \\
\hline & & Women and fathers highly educated \\
\hline & & Up to date with bills \\
\hline & & Mortgage \\
\hline & & Not subjectively poor \\
\hline & & Not receiving means tested benefits \\
\hline & & Not materially deprived \\
\hline \multirow[t]{8}{*}{ "Employed, moderate education, materially deprived" } & \multirow[t]{8}{*}{$14 \%(n=614)$} & Women currently employed \\
\hline & & Father manual and non-manual employment \\
\hline & & Women and fathers medium levels of education \\
\hline & & Moderate behind with bills \\
\hline & & Mortgage and private renting \\
\hline & & Moderate subjective poverty \\
\hline & & Moderate receipt of means tested benefits \\
\hline & & $\begin{array}{l}\text { Material deprived - can't afford holidays, money to replace } \\
\text { good and savings }\end{array}$ \\
\hline \multirow[t]{8}{*}{ "Low education, benefits not materially deprived" } & \multirow[t]{8}{*}{$23 \%(n=992)$} & Women moderate current employment \\
\hline & & Father manual and non-manual employment \\
\hline & & $\begin{array}{l}\text { Women and fathers low levels of education, fathers education } \\
\text { high don't know response }\end{array}$ \\
\hline & & Moderate behind with bills \\
\hline & & Private renting and social housing \\
\hline & & Not subjectively poor \\
\hline & & High receipt of means tested benefits \\
\hline & & Not materially deprived \\
\hline \multirow{8}{*}{$\begin{array}{l}\text { "Low education, benefits, subjectively poor and } \\
\text { materially deprived" }\end{array}$} & \multirow[t]{8}{*}{$18 \%(n=836)$} & Women low current employment \\
\hline & & Father manual employment and unemployed \\
\hline & & $\begin{array}{l}\text { Women and fathers low levels of education, fathers education } \\
\text { high don't know response }\end{array}$ \\
\hline & & Behind with bills \\
\hline & & Private renting and social housing \\
\hline & & Subjectively poor \\
\hline & & High receipt of means tested benefits \\
\hline & & Materially deprived \\
\hline
\end{tabular}

† $n$ based on most likely class membership.

characteristics of the four classes differed. The differences were in the woman's employment status and education, housing, subjective poverty and material deprivation.

We used two different approaches to develop the SEP profiles for these women and the further use of these classes in epidemiological studies will depend upon the research question of interest. If investigating ethnic differences in health across ethnic groups then one overall SEP measure would be required, however if looking at differences in health within ethnic groups our results suggest that it may be more informative to develop ethnic specific SEP classes. Defining classes in other studies may be limited by the availability of the SEP measures in the study.

Our results are consistent with previous research showing that within South Asian ethnic groups there is heterogeneity in SEP with the Indian group found to have higher SEP than Pakistani and Bangladeshi groups [25]. Both the latter groups have been found to have the highest rates of poverty in the UK [26]. In our study we 
Table 7 Description of latent classes from 4 class model solution for Pakistani women

\begin{tabular}{|c|c|c|}
\hline Class & Size of class $(n+)$ & Description \\
\hline \multirow[t]{8}{*}{ "Educated, low benefits, not materially deprived" } & \multirow[t]{8}{*}{$22 \%(n=1113)$} & Women moderate current employment \\
\hline & & Fathers non-manual employment \\
\hline & & Women and fathers highly educated \\
\hline & & Up to date with bills \\
\hline & & Mortgage and owns house outright \\
\hline & & Not subjectively poor \\
\hline & & Not receiving means tested benefits \\
\hline & & Not materially deprivation \\
\hline \multirow{8}{*}{$\begin{array}{l}\text { "Women employed, moderate education, benefits, } \\
\text { not materially deprived" }\end{array}$} & \multirow[t]{8}{*}{$17 \%(n=935)$} & Women current and previously employed \\
\hline & & Father manual employment and self-employed \\
\hline & & Women and fathers medium levels of education \\
\hline & & Moderate behind with bills \\
\hline & & Mortgage \\
\hline & & Not subjectively poor \\
\hline & & High receipt of means tested benefits \\
\hline & & Not materially deprived \\
\hline \multirow{8}{*}{$\begin{array}{l}\text { "Women not employed, low education, benefits, } \\
\text { not materially deprived" }\end{array}$} & \multirow[t]{8}{*}{$33 \%(n=1642)$} & Women low current employment \\
\hline & & Father manual employment and self-employed \\
\hline & & $\begin{array}{l}\text { Women and fathers low levels of education, fathers } \\
\text { education high don't know response }\end{array}$ \\
\hline & & Up to date with bills \\
\hline & & Owns house outright \\
\hline & & Not subjectively poor \\
\hline & & High receipt of means tested benefits \\
\hline & & Not materially deprived \\
\hline \multirow{8}{*}{$\begin{array}{l}\text { "Women not employed, moderate education, benefits, } \\
\text { subjectively poor and materially deprived" }\end{array}$} & \multirow[t]{8}{*}{$28 \%(n=1427)$} & Women low current employment \\
\hline & & Father manual employment, high unemployment \\
\hline & & Women and fathers medium levels of education \\
\hline & & Behind with bills \\
\hline & & Social housing \\
\hline & & Subjectively poor \\
\hline & & High receipt of means tested benefits \\
\hline & & Materially deprived \\
\hline
\end{tabular}

† $\mathrm{n}$ based on most likely class membership.

found that the Indian women were most likely to be in the most affluent group whilst Pakistani and Bangladeshi women were most likely to be in one of the more disadvantaged groups that had a high uptake of means tested benefits but were not materially deprived. This suggests that although they were disadvantaged on some aspects of SEP they are coping or had the support mechanisms available to support themselves financially. Other research has also found that factors relating to standard of living [27,28] and asset based measures [5] are important measures of SEP in ethnic groups in addition to measures such as education and occupational social class.

\section{Strengths and limitations}

To our knowledge this is the first time latent class analysis has been used to study the association between SEP and ethnicity in the UK. The key strengths are the large sample size and the inclusion of multiple measures of different dimensions of SEP. We used all available data on each category for each indicator including any missing responses ensuring the sample size was as large as possible. By including 19 different indicators of SEP including 11 questions about ownership of material deprivation items we were able to obtain a detailed description of how these women actually live and perceive 


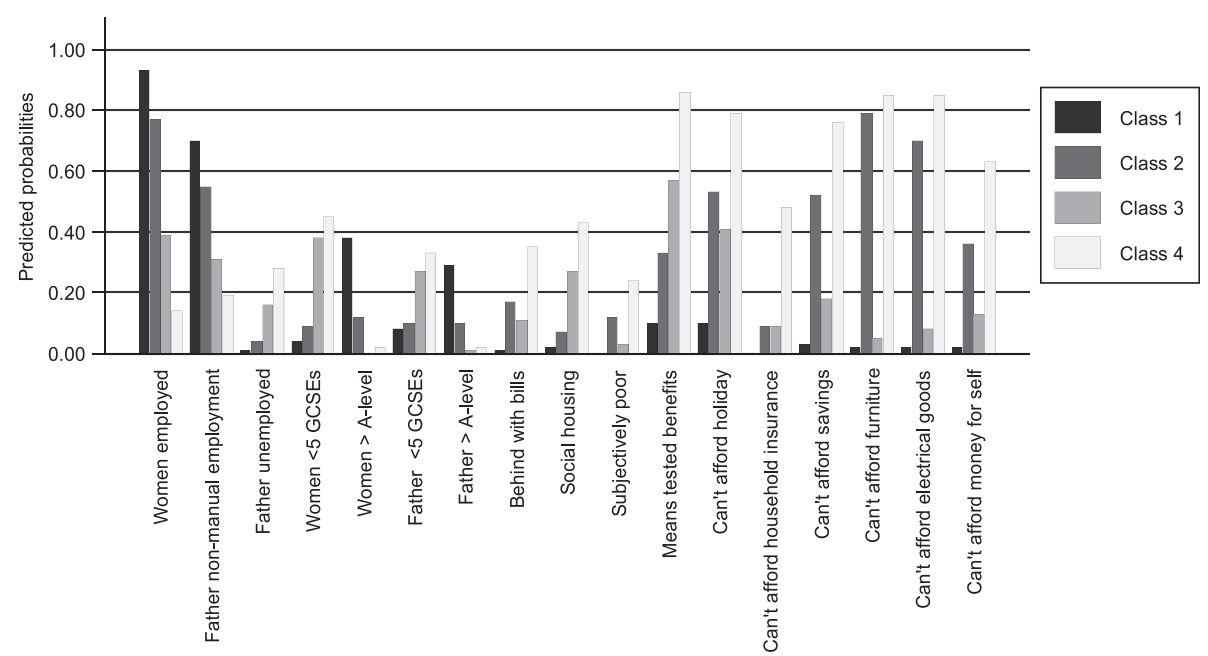

Figure 2 Summary of selected predicted probabilities for levels of SEP indicators from 4 class model for White British women. Class 1: "Employed, educated and not materially deprived" (44\%, n= 2038 (based on most likely class membership)). Class 2: "Employed, moderate education, materially deprived" $(14 \%, n=614)$. Class 3: "Low education, benefits not materially deprived" $(23 \%, n=992)$. Class 4: "Low education, benefits, subjectively poor and materially deprived" $(18 \%, n=836)$.

deprivation in their day to day lives, this may not have been captured by using only traditional indicators of SEP.

There are some limitations to this work. Firstly we could not include a measure of income in our models for two reasons; over the recruitment period of the study different questions on income were asked, and the question asked about the income of the woman and her husband/partner not the household income. Many studies use equivalised household income however we cannot derive this from the information we have collected in this study.
We did not include a measure of occupational social class for the women. However there are problems with assigning social class to women as many women will not have an occupational social class if they are at home looking after the family. In our study we found that over a quarter of women had never been employed and so could not be assigned to an occupational social class. In our analysis we also did not capture any differences in household size and composition and this will vary by ethnic group. This could be further researched, along with exploring similarities and contrasts in what the measures of SEP mean to different ethnic groups.

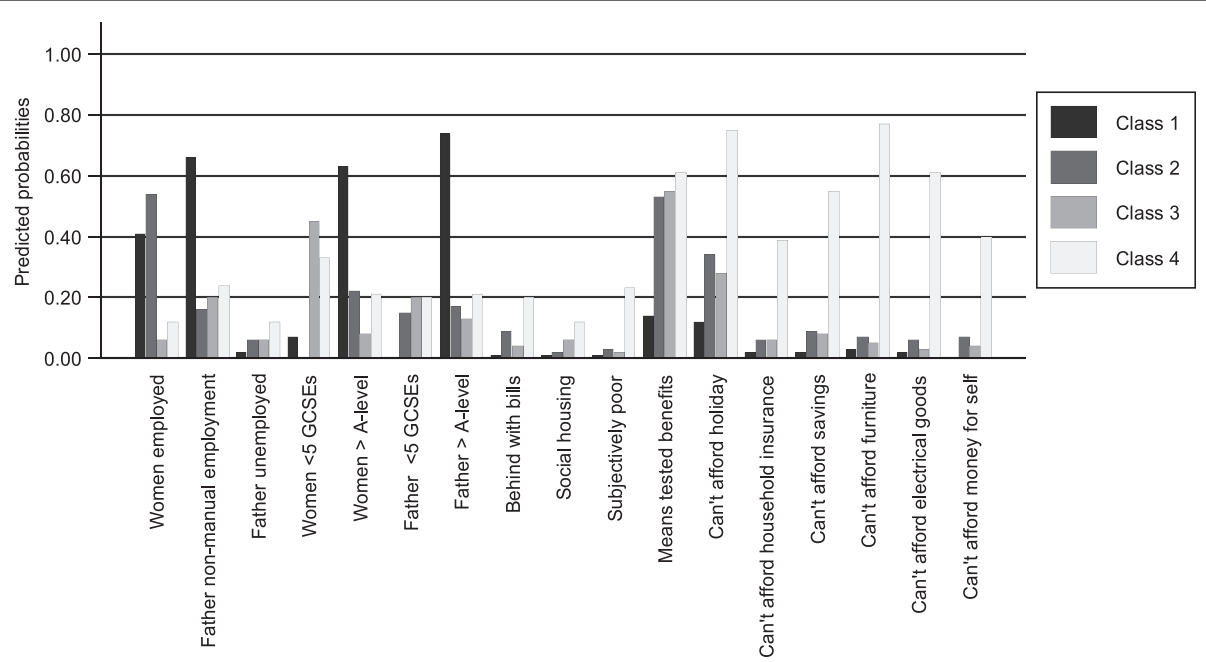

Figure 3 Summary of selected predicted probabilities for levels of SEP indicators from 4 class model for Pakistani women. Class 1: "Educated, low benefits, not materially deprived" (22\%, $\mathrm{n}=1113$ (based on most likely class membership)). Class 2: "Women employed, moderate education, benefits, not materially deprived" (17\%, $N=935)$. Class 3: "Women not employed, low education, benefits, not materially deprived" $(33 \%, n=1642)$. Class 4: "Women not employed, moderate education, benefits, subjectively poor and materially deprived" $(28 \%, n=1427)$. 
The study offers a way of conceptualising SEP and ethnicity that reflects the complexity of the relationship between these two areas. Our findings support the hypothesis that before exploring the relationship between SEP, ethnicity and health adequate measures of SEP must be conceptualised and captured from real life data. The classes identified can now be linked to health outcomes over time to investigate the relationship between SEP, ethnicity and health. This method can also be used to capture changes in SEP profiles longitudinally.

\section{Conclusions}

Latent class analysis is an approach that allows different aspects of an individual's social and economic position to be considered in one multidimensional indicator and avoids narrow categorisation of SEP. These findings help us understand the role of different components of SEP within ethnic groups and the classes defined and described here can be used in future analyses investigating the relationship between ethnicity and health ensuring appropriate adjustment for SEP confounding.

\section{Abbreviations}

SEP: Socioeconomic position; LCA: Latent class analysis; FIML: Full information maximum likelihood; RRR: Relative risk ratio.

\section{Competing interests}

The authors declare that they have no competing interests.

\section{Authors' contributions}

$L F, B C, N S, E S P, D A L$ and JW made substantive contributions to the conception and design of the study. LF carried out the analysis and drafted the paper. All authors contributed to interpretation and critical revisions of the paper. All authors have read and approved the final version of the manuscript.

\section{Acknowledgements}

Born in Bradford is only possible because of the enthusiasm and commitment of the Children and Parents in BiB. We are grateful to all the participants, health professionals and researchers who have made Born in Bradford happen.

This paper presents independent research funded by the National Institute for Health Research Collaboration for Applied Health Research and Care (NIHR CLAHRC). The views expressed in this publication are those of the author(s) and not necessarily those of the NHS, the NIHR or the Department of Health.

\section{Author details}

'Bradford Institute for Health Research, Bradford Teaching Hospitals NHS Foundation Trust, Bradford, UK. ${ }^{2}$ Faculty of Medicine, Universidad del Desarrollo, Santiago, Chile. ${ }^{3}$ School of Health Studies, University of Bradford, Bradford, UK. ${ }^{4}$ MRC Centre for Causal Analyses in Translational Epidemiology, School of Social and Community Medicine, University of Bristol, Bristol, UK. ${ }^{5}$ Department of Health Sciences, University of York, York, UK.

Received: 19 November 2013 Accepted: 31 July 2014

Published: 12 August 2014

\section{References}

1. Krieger N: A glossary for social epidemiology. J Epidemiol Community Health 2001, 55(10):693-700.
2. Galobardes B, Shaw M, Lawlor DA, Lynch JW, Davey SG: Indicators of socioeconomic position (part 1). J Epidemiol Community Health 2006, 60(1):7-12.

3. Galobardes B, Shaw M, Lawlor DA, Lynch JW, Davey SG: Indicators of socioeconomic position (part 2). J Epidemiol Community Health 2006, 60(2):95-101.

4. Howe LD, Galobardes B, Matijasevich A, Gordon D, Johnston D, Onwujekwe O, Patel R, Webb EA, Lawlor DA, Hargreaves JR: Measuring socio-economic position for epidemiological studies in low- and middle-income countries: a methods of measurement in epidemiology paper. Int J Epidemiol 2012, 41(3):871-886.

5. Kelaher M, Paul S, Lambert H, Ahmad W, Smith GD: The applicability of measures of socioeconomic position to different ethnic groups within the UK. Int J Equity Health 2009, 8:4.

6. Braveman PA, Cubbin C, Egerter S, Chideya S, Marchi KS, Metzler M, Posner S: Socioeconomic status in health research: one size does not fit all. JAMA 2005, 294(22):2879-2888.

7. Hagenaars J, McMutcheon A: Applied latent class analysis. Cambridge: Cambridge University Press; 2009.

8. Acock AC: Working with missing values. J Marriage Fam 2005, 67(4):1012-1028.

9. Enders CK: A primer on maximum likelihood algorithms available for use with missing data. Struct Equation Model 2001, 8(1):128-141.

10. Baker $\mathrm{D}$, Taylor $\mathrm{H}$ : Inequality in health and health service use for mothers of young children in south west England. survey team of the avon longitudinal study of pregnancy and childhood team. J Epidemiol Community Health 1997, 51(1):74-79.

11. Savage M, Devine F, Cunningham N, Taylor M, Li Y, Hjellbrekke J, Le Roux B, Friedman S, Miles A: A new model of social class? findings from the BBC's Great British Class survey experiment. Sociol 2013, 47(2):219-250.

12. Scharoun-Lee M, Kaufman JS, Popkin BM, Gordon-Larsen P: Obesity, race/ethnicity and life course socioeconomic status across the transition from adolescence to adulthood. J Epidemiol Community Health 2009, 63(2):133-139.

13. Scharoun-Lee M, Gordon-Larsen P, Adair LS, Popkin BM, Kaufman JS, Suchindran CM: Intergenerational profiles of socioeconomic (dis)advantage and obesity during the transition to adulthood. Demography 2011, 48(2):625-651

14. Dahly D, Gilthorpe M: A latent class analysis of socioeconomic status and obesity in young adults from Cebu, Philippeans. J Epidemiol Community Health 2011, 65(Suppl 1):A71.

15. Wright J, Small N, Raynor P, Tuffnell D, Bhopal R, Cameron N, Fairley L, Lawlor DA, Parslow R, Petherick ES, PIckett KE, Waiblinger D, West J on behalf of the Born in Bradford Scientific Collaborators Group: Cohort profile: The Born in Bradford multi-ethnic family cohort study. Int J Epidemiol 2013, 42(4):978-991.

16. Rose D, Pevalin DJ: A Researcher's Guide to the National Statistics Socio-Economic Classification. London: Sage; 2003.

17. UK NARIC. [http://ecctis.co.uk/naric/] (Last accessed 30 3 th $^{\text {th }}$ August 2013).

18. Bradshaw J, Holmes J: Family poverty assessed at three years old. In CLS Working Paper. London: Centre for Longitudinal Studies; 2008.

19. Adams N, Carr J, Collins J, Johnson G, Matejic P: Households Below Average Income: An analysis of the income distribution 1994/95-2010/11. London: Department of Work and Pensions; 2012.

20. Office for National Statistics: Ethnic Group Statistics: A guide for the collection and classification of ethnicity data. London: The Stationary Office; 2003.

21. Muthen LK BOM: (1998-2012): Mplus User's Guide. 7th edition. Los Angeles, CA: Muthen and Muthen; 2012.

22. Nylund KL, Asparouhiv T, Muthen BO: Deciding on the number of classes in latent class analysis and growth mixture modelling. Struct Equation Model 2007, 14(4):535-569.

23. Muthen B, Muthen LK: Integrating person-centered and variable-centered analyses: growth mixture modeling with latent trajectory classes. Alcohol Clin Exp Res 2000, 24(6):882-891.

24. StataCorp: Stata Statistical Software release 12. College Station, TX: StataCorp LP; 2011.

25. Nazroo JY: Ethnicity, Class and Health. London: Policy Studies Institute; 2001.

26. Plant L: Poverty and ethnicity in the UK. Bristol: Joseph Rowentree Foundation; 2007. 
27. Nazroo JY: The structuring of ethnic inequalities in health: economic position, racial discrimination, and racism. Am J Public Health 2003, 93(2):277-284.

28. Chandola T: Ethnic and class differences in health in relation to British South Asians: using the new National Statistics Socio-Economic Classification. Soc Sci Med 2001, 52(8):1285-1296.

doi:10.1186/1471-2458-14-835

Cite this article as: Fairley et al: Using latent class analysis to develop a model of the relationship between socioeconomic position and ethnicity: cross-sectional analyses from a multi-ethnic birth cohort study. BMC Public Health 2014 14:835.

\section{Submit your next manuscript to BioMed Central and take full advantage of:}

- Convenient online submission

- Thorough peer review

- No space constraints or color figure charges

- Immediate publication on acceptance

- Inclusion in PubMed, CAS, Scopus and Google Scholar

- Research which is freely available for redistribution 